\title{
A EDUCAÇÃO NÃO FORMAL E SUA INTERFACE COM A PEDAGOGIA SOCIAL: CONCEITO, CONTEXTO E PROPOSIÇÕES DA FORMAÇÃO DO SUJEITO CIDADÃO
}

\author{
LA EDUCACIÓN NO FORMAL Y SU INFERFAZ COM LA PEDAGOGÍA SOCIAL: \\ CONCEPTO, CONTEXTO Y PROPOSICIONES ACERCA DE LA FORMACIÓN DEL \\ SUJETO CIUDADANO
}

\begin{abstract}
NON-FORMAL EDUCATION AND ITS INTERFACE WITH SOCIAL PEDAGOGY: CONCEPT CONTEXT AND PROPOSITIONS ABOUT THE FORMATION OF THE CITIZEN SUBJECT
\end{abstract}

Daniella Caroline Rodrigues Ribeiro FERREIRA ${ }^{1}$
Adriana Regina de Jesus SANTOS ${ }^{2}$

RESUMO: O presente estudo tem como temática central a educação não formal, e como objetivo norteador refletir acerca da importância da Educação não formal e sua relação com a Pedagogia Social, a fim de identificar suas implicações na formação do sujeito cidadão. A metodologia utilizada foi a pesquisa bibliográfica e de campo. No que se refere à pesquisa bibliográfica foram selecionados autores tais como: Coutinho (2009); Freire (2007) Ferreira (2010), Fernandes; Garcia (2006), Libâneo (2007), entre outros. Em relação à pesquisa de campo, foi realizada uma observação no que tange ao espaço não formal chamado de Vila Cultural, localizado na cidade de Londrina. Foi possível constatar ao término desta pesquisa a necessidade de compreender a importância da educação não formal e da pedagogia social na formação do sujeito, uma vez que esta modalidade de ensino tem como pressuposto a emancipação, a autonomia e a criticidade, princípios estes que tendem a formar um cidadão que possa realizar uma leitura de mundo tendo como parâmetro o contexto social, político, econômico, cultural e educacional onde está inserido.

PALAVRAS-CHAVE: Educação não formal. Pedagogia social. Cidadão. Emancipação.

RESUMEN: El presente estudio tiene como temática central, la educación no formal, y como objetivo orientador reflexionar acerca de la importancia de la Educación no formal y su relación con la Pedagogía Social, a fin de identificar sus implicaciones en la formación del sujeto ciudadano. La metodología utilizada fue a partir de la investigación bibliográfica y de campo. En lo que se refiere a la investigación bibliográfica fueron seleccionados autores

\footnotetext{
${ }^{1}$ Universidade Estadual de Londrina - (UEL), Londrina - PR - Brasil. Centro de Educação Comunicação e Artes, Londrina - Paraná-Brasil. Mestranda pelo programa de pós-graduação em Educação da Universidade Estadual de Londrina. Integrante do Grupo de Pesquisa cadastrado no CNPq: Currículo, formação e trabalho docente. Orcid: http://orcid.org/0000-0001-8691-4089. E-mail: daniellacarolinef@gmail.com

${ }^{2}$ Universidade Estadual de Londrina - (UEL), Londrina - PR - Brasil. Centro de Educação Comunicação e Artes, Londrina - Paraná-Brasil. Pós Doutora em Educação na Universidade Federal Fluminense. Docente do Curso de Pedagogia e do Programa de Mestrado e Doutorado em Educação da Universidade Estadual de Londrina. Líder do Grupo de Pesquisa cadastrado no CNPq: Currículo, formação e trabalho docente. Orcid: http://orcid.org/0000-0002-9346-5311. E-mail:adrianatecnologia@yahoo.com.br
}

RIAEE - Revista Ibero-Americana de Estudos em Educação, Araraquara, v. 14, n. 4, p. 2275-2286, out./dez., 2019. e-ISSN: 1982-5587. DOI: https://doi.org/10.21723/riaee.v14i4.11975 
tales como: Coutinho (2009); Freire (2007) Ferreira (2010), Fernandes; Garcia (2006), Libâneo (2007) entre otros. En relación a la investigación de campo, se realizó una observación en lo que se refiere al espacio no formal llamado Vila Cultural, ubicado en la ciudad de Londrina. En el caso de la educación no formal y de la pedagogía social en la formación del sujeto, una vez que esta modalidad de enseñanza tiene como presupuesto la emancipación, la autonomía y la criticidad, principios que tienden a formar un ciudadano que pueda realizar una lectura de mundo teniendo como parámetro, el contexto social, político, económico, cultural y educativo donde está inserto.

PALABRAS CLAVE: Educación no formal. Pedagogía social. Ciudadana. Emancipación

ABSTRACT: The main objective of this study is to study non - formal education and its objective to reflect on the importance of non - formal education and its relationship with social pedagogy, in order to identify its implications for the formation of the citizen subject. The methodology used was based on bibliographical and field research. As far as bibliographic research was concerned, authors such as: Coutinho (2009); Freire (2007) Ferreira (2010), Fernandes; Garcia (2006), Libâneo (2007) among others. In relation to field research, an observation was made regarding the non-formal space called Cultural Village, located in the city of Londrina. It was possible to verify at the end of this research the need to understand the importance of non-formal education and social pedagogy in the formation of the subject, since this modality of teaching has as a presupposition emancipation, autonomy and criticality, principles that tend to to form a citizen who can carry out a world reading based on the social, political, economic, cultural and educational context in which he / she is inserted.

KEYWORDS: Non-formal education. Social Pedagogy. Citizen. Emancipation.

\section{Introdução}

Este estudo é fruto das discussões e estudos realizados em grupo de pesquisa cadastrado no CNPq, que possibilitou perceber a necessidade de compreender e conhecer a realidade do espaço não formal, tendo como foco entender como este se configura e os desafios atuais encontrados. Isto posto, temos como objetivo analisar a importância da Educação não formal e sua relação com a Pedagogia Social, a fim de perceber suas implicações na formação do sujeito envolvido nesta modalidade.

Para entender melhor a temática objeto do nosso estudo, a metodologia utilizada teve como parâmetro a pesquisa bibliográfica e de campo, que nos possibilitou uma reflexão crítica deste espaço formativo. Sendo assim, este artigo está estruturado da seguinte maneira: em um primeiro momento analisou-se o contexto e a importância da Educação Não Formal e da Pedagogia Social, tendo como base a realização de uma revisão bibliográfica. Em um segundo momento descreveu-se a metodologia utilizada na pesquisa de campo, bem como a 
possibilidade de uma proposta de intervenção acerca do espaço não formal, a fim de possibilitar aos professores, pesquisadores, estudantes desta área uma reflexão crítica em relação ao processo formativo.

\section{A Importância da Educação Não Formal e a Pedagogia Social}

No contexto da sociedade contemporânea é possível evidenciar o quanto ainda são restritos os estudos sobre a prática de educação não formal, embora diversos seguimentos da sociedade venham direcionando o olhar para esta pedagogia social como campo de conhecimento e de ação profissional. Iniciando os estudos a respeito desta temática, contatamos a necessidade da academia e da sociedade civil entenderem o quanto a pedagogia social é imprescindível para a educabilidade social do sujeito.

Partindo deste pressuposto, os autores Silva; Souza Neto; Moura (2009) definem a pedagogia social como: "uma ciência normativa, descritiva, que orienta a prática sociopedagógica voltada a formação humana, autônoma e emancipada, proporcionando aos sujeitos analisar as condições de desigualdades sociais, superando, dessa maneira, possíveis vulnerabilidades a que estão expostos, com um intuito educativo.

Contribuindo com essa reflexão, Gohn (2010) afirma que a pedagogia social constitui uma possibilidade de dar respostas às necessidades educativas do mundo contemporâneo, com propostas destinadas a um público determinado, com objetivos específicos. Já a educação não formal, na visão da autora, tem caráter universal, visualiza processos educativos de aprendizagem e produção de saberes na sociedade como um todo.

Portanto, segundo os autores:

[...] as práticas da educação não formal são passíveis de serem aplicadas a todos os grupos etários, de todas as classes sociais e em contextos socioculturais diversos [...] o trabalho com essa modalidade educativa não implica e nem exige, em princípio, uma diferenciação de classe (SIMSON; PARK; FERNANDES, 2007, p. 23).

Assim sendo, a consolidação da pedagogia social ocorre preferencialmente, ainda que não exclusivamente, na educação não formal. Para tanto, necessita pensarmos em um currículo e um planejamento adequado para o atendimento dos sujeitos que serão atendidos por este espaço. As instituições de educação não formal se caracterizam, ainda, “[...] pela maior flexibilidade de campo e liberdade de escolher os conteúdos, bem como ser uma de iniciativa voluntária e não obrigatória [...]” (FERNANDES; GARCIA, 2006, p. 11). 
Continuando os apontamentos, os autores destacam que estes espaços promovem o desenvolvimento e o enriquecimento da sociabilidade, pois envolvem atividades que possibilitam a participação de pessoas de diversas faixas etárias e experiências sociais. A socialização e a troca de experiência desses sujeitos durante a realização das atividades acabam enriquecendo o trabalho nessas instituições. Os principais benefícios destes trabalhos, além do citado acima, é o provimento do sentimento de pertencimento "[...] aumento da autoestima, (re) construção da personalidade e identidade, formação dos vínculos afetivos [...], desenvolvimento do processo criativo e imaginação" (FERNANDES; GARCIA, 2006, p. $11)$.

Assim, devem ser considerados os desejos e anseios da comunidade com a qual se pretende trabalhar, partindo de estudos, do conhecimento da realidade em questão, fazendo uma integração com as ações a serem desenvolvidas.

Tendo como parâmetro as reflexões postas acerca da educação não formal e da pedagogia social, fica claro que não há como pensar esta modalidade sem levar em consideração a comunidade, pois quando a escola é entendida e vista como um espaço social, levando em conta os constantes processos de construção de identidade, sendo eles de caráter pessoal e social, automaticamente tem-se que pensar em práticas que o tempo todo nos faça manter parceiros da sociedade, favorecendo processos, onde a mesma possa integrar e transformar.

\section{Metodologia e Lócus da Pesquisa}

Faz-se relevante ressaltar que a pesquisa realizada se deu por meio de reuniões e discussões realizadas no grupo de pesquisa cadastrado no CNPq: Currículo, formação e trabalho docente. Após essa formação, entramos em contato com o nosso lócus de pesquisa, solicitando realizar observações e intervenções no contexto da prática educacional. Obtivemos uma resposta positiva e fomos autorizados a desenvolver este estudo na Vila Cultural, localizada na cidade de Londrina, estado do Paraná. O Espaço tem uma capacidade máxima para atender 50 pessoas, possui dois banheiros, um pátio externo, uma sala de edição, uma secretaria, um almoxarifado, uma sala de exposição e outra de recepção. O seu horário de funcionamento é das $13 \mathrm{~h} 30 \mathrm{~min}$ até às 20h00min horas ou até acabarem as apresentações realizadas.

A vila cultural foi construída por meio de um edital de 2012 (o qual trata sobre as vilas culturais), sendo este assumido em outubro deste mesmo ano e inaugurado em março de 2013. 
Foi criado com a finalidade de atender a região oeste da cidade de Londrina, pois nesta região não havia nenhum espaço cultural, fazendo com que diversas crianças por muitas vezes ficassem nas ruas, sem um amparo sócio educacional. Diante disso, a Secretaria de Cultura autorizou o funcionamento da Vila Cultural com o objetivo de oferecer um espaço para que crianças e adolescentes pudessem participar das atividades culturais no período que não estivessem em aula na escola regular.

Conforme uma das pessoas responsáveis pela Vila Cultural, o espaço recepciona também grupos de teatro ou então atores e atrizes que queiram fazer trabalho solo, disponibilizam também para música, projetos e cursos, sempre com o fim educativo e cultural. Em relação ao público atendido, quando os coordenadores responsáveis planejam apresentações culturais, principalmente teatro e espetáculos de palhaços, contam em média com cinquenta pessoas por espetáculo (famílias da região e vindas de fora). No que se refere a projetos e oficinas com crianças, geralmente atendem em média de vinte a trinta pessoas.

Durante as observações realizadas no espaço da Vila Cultural, constatamos a inexistência de um projeto político pedagógico e nem documento específico acerca da sua missão e objetivo. Por meio da entrevista realizada neste espaço identificamos pelas falas dos colaboradores que "a falta destes documentos e a não presença e a atuação de um pedagogo acarretava em uma ação fragilizada", pois entendem que este profissional poderia fomentar discussões pedagógicas e sistematizar as atividades a serem desenvolvidas.

Contribuindo com essa reflexão, o autor Libâneo (2007) diz que a sistematização das atividades e de uma proposta de trabalho voltada para o espaço educativo é enriquecedor, mas para tal, o autor defende que o pedagogo, juntamente com os integrantes, promova e organize pedagogicamente o espaço da educação formal e não formal.

\section{Possibilidade de um repensar acerca do espaço da Educação não formal}

No que se refere à organização das intervenções, em um primeiro momento analisamos o lócus da pesquisa, e pensamos a respeito com base no amparo teórico das reuniões em grupo. Optamos em apresentar aos sujeitos envolvidos no projeto Vila Cultural algumas ações didático pedagógicas que pudessem contribuir para o repensar do trabalho pedagógico e ao mesmo tempo contribuir com a formação das crianças e adolescentes envolvidos.

A temática uso dos recursos audiovisuais como espaço de formação foi a primeira atividade anunciada. $\mathrm{O}$ tema surgiu em virtude de perceber que a utilização dessas tecnologias 
de informação e comunicação faz parte do cotidiano desses sujeitos nativos digitais. Quanto aos procedimentos metodológicos desta intervenção, propomos a criação de um canal no Youtube, (uma plataforma on-line de compartilhamento de vídeos) de forma que pudesse contribuir para o desenvolvimento de atividades formativas com conteúdos que remetam às questões de cultura, cidadania, introdução das tecnologias da informação e a percepção que por meio deste recurso é possível registrar as memórias dos trabalhos desenvolvidos. Um dos principais objetivos em proporcionar esta intervenção seria também referente à integração e à socialização dos conteúdos que remetam à cidadania por meio de recursos audiovisuais.

Outros objetivos norteadores foram selecionados, tais como: Promover atividades que despertam o sentimento de pertencimento do educando em relação à instituição educativa, desenvolver atividades práticas com recursos audiovisuais e, por fim, possibilitar a produção coletiva de materiais por meio de diferentes recursos (textos, vídeos, jogos, música, dança, entre outros).

Atualmente em razão da ênfase nas tecnologias de informação e comunicação, entendemos que a utilização destes como ferramenta educativa pode contribuir de maneira significativa no processo educacional. Sobre a importância do uso destas ferramentas, a autora Alba nos revela que:

As tecnologias trazem um imenso leque de recursos didáticos para lhes dar oportunidade de responder às diferenças individuais e às múltiplas facetas de sua aprendizagem, proporcionando meios variados, ferramentas e métodos, graças à flexibilidade que têm as tecnologias para se adaptar às diferentes necessidades, ajudando a superar as dificuldades e apoiando-se nos aspectos com maior potencial (ALBA, 2006, p. 148).

Os recursos audiovisuais tais como (cinema, séries, documentários) estão ligados a um contexto de lazer, de entretenimento. Na cabeça dos alunos, quando se trata de cinema, série televisiva, documentários, vídeos, significa descanso, diversão e não de fato "aula", o que modifica a postura e suas expectativas em relação ao uso, pois desperta o interesse em querer participar.

Segundo Ferreira (2010), os recursos partem do concreto, visível, imediato e do próximo, utilizam o corpo, tocam-nos e podemos tocar os outros, estão ao nosso alcance por meio dos recortes visuais, sentimos, experimentamos e temos sensações sobre o que estamos vendo, sobre o mundo e até mesmo sobre nós mesmos. Explora também o ver, o visualizar, o ter diante de nós, observaram as pessoas, os cenários, cores, etc.

Desenvolvem também um olhar com múltiplos recortes da realidade através dos planos, e muitos ritmos visuais: imagens estáticas e dinâmicas, câmera fixa ou em 
movimento, uma ou várias câmeras, personagens quietas ou em movimento, imagens ao vivo, gravadas ou criadas no computador. Um ver que está situado no presente, mas que o interliga não linearmente com o passado e com o futuro.

Sendo assim, é preciso criar novas metodologias com atividades interessantes e significativas para alcançar os nativos digitais, proporcionando-lhes o estímulo à exploração, à autoexpressão. Bem como a comunicação, a socialização, a colaboração e a integração dos educandos da instituição.

\section{Práticas e Realidades no Espaço Não Formal: uma experiência que nos encantou}

No que se refere às nossas práticas na realidade do espaço não formal, estas foram extremamente significativas, e nossa participação foi contínua em todo o processo. No primeiro dia, contamos com a participação de 10 crianças, com a faixa etária entre 8 e 12 anos. Um dos coordenadores responsáveis pelo espaço (considerados como educadores da Vila Cultural) iniciou a aula, com uma dinâmica em grupo, uma atividade de brincadeira, a fim de possibilitar um clima confortável e socialização com os demais integrantes: crianças e educadores.

Resumidamente, a dinâmica era baseada em formar uma roda, para que em um primeiro momento todos falassem os seus nomes, em seguida uma pessoa dizia o nome de alguém que estava na roda, e essa pessoa tinha que falar o nome e fazer uma abertura (bater palmas, fazer algum barulho, alguma dança, etc.).

As crianças adoraram este momento, e estavam à vontade com os demais alunos, em seguida, desenvolvemos com estes o que tínhamos planejado, juntamente com os coordenadores do Projeto Vila Cultural.

Foi apresentado às crianças que iríamos desenvolver um canal do Youtube, e que para isso acontecer era preciso conhecer alguns canais, e então perguntamos para elas quais eram os seus canais preferidos, para assim destacarmos informações necessárias, que pudéssemos utilizar na prática quando fosse para desenvolver os vídeos. Foram observados nos vídeos assistidos: efeitos, gravação, som, música, os equipamentos, figurino das pessoas, cenários, edição do vídeo, etc.

Em seguida, solicitamos que cada um falasse duas coisas que mais gosta de fazer no mundo, tendo como foco identificar possíveis assuntos que pudessem ser trabalhados no vídeo. Cada um falou suas coisas preferidas, e com base nisto ficou como tarefa para o 
próximo encontro cada um pensar e apresentar cinco nomes possíveis para colocarmos no canal.

Finalizando as atividades, o coordenador solicitou um momento para apresentar um vídeo de um canal do Youtube, sobre como fazer um Spinner (um brinquedo que serve como um amenizador da ansiedade e do estresse. Consiste num equipamento que quando impulsionado começa a girar constantemente na ponta dos dedos do seu usuário. Também é conhecido como fidget spinner ou fidget hand spinner). Geralmente é feito com materiais simples do cotidiano, neste vídeo era usado corrente de bicicleta e rolamento de bicicleta para a sua confecção.

Após assistir ao vídeo, desenvolvemos com os educandos a produção do Spinner; ocorreram algumas dificuldades em relação aos materiais, pois alguns não estavam dando certo, o momento de encaixar a corrente, etc, porém, no final, foi ajustada, e cada educando saiu feliz com o seu brinquedo, podendo então levá-lo para casa.

No encontro seguinte, conversando com os educandos, estes escolherem o seguinte nome para o canal do Youtube: "O mundo das engenhocas", onde desenvolveríamos vários temas para colocarmos no canal. Conversando com o grupo, ficou decidido que o primeiro tema seria Cinema.

Para o próximo encontro, ficou combinado de cada educando trazer algumas pesquisas sobre características do cinema, tais como: filmes antigos e clássicos, lançamentos, curiosidades, erros de gravação, história do cinema, animação, tecnologia, etc. E que também pesquisassem um filme favorito e suas características.

Para finalizar o dia, foi apresentada uma proposta para os educandos fazerem uma apresentação individual para colocarmos no nosso canal, e por último uma apresentação coletiva onde gritariam o nome do canal. Esta atividade foi de extrema importância, pois notamos o quanto os mesmos estavam entusiasmados com esta ideia de se apresentar. Cada um escreveu sua apresentação em um papel; foi um momento bem rico, com muitas experiências.

Vale destacar que o começo das aulas era sempre iniciado com uma dinâmica incluindo a ludicidade e as brincadeiras: os educandos adoravam este momento, e sempre queriam brincar cada vez mais.

Dando continuidade, em outro momento solicitamos para os educandos apresentarem o que haviam pesquisado sobre o tema Cinema. Neste momento começaram a aparecer alguns desafios, pois estes não sabiam como fazer uma pesquisa; muitos não tinham acesso ao computador. É neste momento em que o educador responsável, ao planejar suas aulas, deve 
sempre ter em mente alguma coisa caso esses tipos de imprevistos aconteçam. Como sabíamos que isto poderia ocorrer, pesquisamos em casa sobre as temáticas e trouxemos para os alunos, passando novamente no Datashow. Foi um momento muito rico, pois os educandos perceberam que mesmo eles não trazendo todas as informações conseguiram dar continuidade no assunto, pelo qual eles gostaram bastante.

Destarte, fomos a uma sala que continha um computador, e juntamente com os educandos, editamos cada vídeo das apresentações individuais, com o intuito de colocarmos no canal. Vale salientar que as crianças levaram para casa um termo de consentimento para que os responsáveis assinassem, autorizando a publicização do vídeo. Os educandos adoraram editar os vídeos, mas sempre ficavam perguntando: "Quando teremos as brincadeiras? Queremos brincar”. E, no final, fizemos mais uma dinâmica com eles, para finalizar o dia.

Em um outro dado momento, chegando à instituição, para dar início às atividades, tivemos uma conversa com os educandos e percebemos que os mesmos não estavam achando interessante trabalhar o tema cinema, e relataram que queriam mais brincadeiras e dinâmicas. Sendo assim, em conjunto, decidimos mudar o nome do canal para "Brincando de jogar". Identificamos nesse processo autonomia, crítica reflexiva e emancipação desses sujeitos, pois estes ficaram felizes, demonstrando valor de pertencimento nas ações que estávamos realizando.

Neste dia já aconteceu uma gravação, os educandos apresentaram a seguinte proposta de brincadeira: pega bandeira. Sendo assim, foi produzido um vídeo explicando as regras da referida brincadeira e após a explicação eles demonstraram como era a brincadeira na prática.

Chegando aos últimos momentos de intervenção, apresentamos o vídeo finalizado para os educandos e em seguida conversamos a respeito do que eles acharam de tal atividade. Os educandos relataram que gostaram muito, e que queriam manter o nome do canal com foco nas brincadeiras, pois achavam que "é mais a cara da turma", já que eles adoravam brincar, nada mais justo do que falar das brincadeiras, e poderiam, com o canal, estimular outras pessoas a brincarem em suas casas, com diversas brincadeiras que eles iriam explicar.

Após este momento, apresentamos o vídeo para todos verificarem a possível aprovação para publicarmos no canal. Assistimos aos vídeos reproduzidos pelo computador por meio do recurso Datashow, conversamos um pouco a respeito, e decidimos publicá-lo em nosso canal. Notei nesse momento a empolgação dos educandos ao assistirem os vídeos e verem suas atuações, foi um momento muito importante e significativo para todos.

Ainda sobre esta temática, é importante salientar que a falta de estrutura do Projeto Vila Cultural em relação a equipamentos, espaço físico e pedagógico interferiu um pouco 
nesse processo, pois tínhamos apenas um computador para pensar na produção de vídeo. Mas isso não trouxe desânimo, pelo contrário, mobilizou pensar no coletivo. Contribuindo com essa reflexão, Freire (2003) ressalta que o papel do educador é auxiliar o educando a se descobrir, ou seja, que mesmo diante das dificuldades podemos construir um momento de prazer e de alegria. Sendo assim, devemos sempre estar atentos em relação aos educandos, tendo ciência de que o prazer e a alegria são itens indispensáveis para a formação humana, política, autônoma e emancipada do sujeito.

Freire (2007) continua sendo um referencial em relação a esta formação humana, pois em seus escritos sempre defendeu que temos que levar em consideração no processo formativo o contexto real dos envolvidos, identificando sua atmosfera social, para que assim ocorra uma participação de um ensino comprometido.

Portanto, é com este comprometimento que devemos pensar a respeito da educação não formal e da pedagogia social, pois devemos analisar, rever, pensar e organizar as ações educativas de acordo com o contexto do educando, possibilitando que este vá além da codificação de letras, e passe a fazer uma leitura de mundo.

As trocas de experiências que esta modalidade de ensino nos proporcionou são de extrema importância para a formação de um educador crítico e que consiga visualizar a educação em diferentes níveis de ensino.

\section{Considerações finais}

Diante das reflexões apontadas neste estudo, é possível perceber a importância do espaço não formal e da pedagogia social na formação humana do sujeito, bem como a contribuição desta na construção de práticas socioeducativas, relacionando e promovendo a socialização em determinado contexto.

Sendo assim, necessitam compreender que a educação não formal e a pedagogia social estão interligadas. Estas têm como princípio proporcionar aos educandos olhar além das dependências escolares, o que provoca a possibilidade de uma leitura de mundo ancorada em uma matriz da totalidade, implicando neste sujeito a possibilidade de visualizar o contexto social além da microestrutura, isto é, da janela da sua casa.

O Espaço da pesquisa de campo gerou uma oportunidade extremamente rica, onde relacionamos a teoria com a prática observada na realidade, o que nos moveu a identificar os desafios e contribuições deste espaço no âmbito acadêmico e social. 
Foram adquiridas experiências significativas para as reflexões, pois ficou evidente o quanto a educação não formal e a pedagogia social oferecem diversas oportunidades de aprendizagens, e o quanto o papel do educador neste espaço é importante para a compreensão do contexto social. Será nesta perspectiva que o educador poderá oportunizar momentos significativos de acordo com todas as especificidades e a realidade social.

Percebemos na prática vivenciada também o quanto as atividades e as dinâmicas por meio do lúdico despertam a curiosidade e o interesse dos educandos. Podemos concluir dizendo o quanto o espaço não formal dentro do âmbito educacional é extremamente rico e contém a sua própria especificidade, que por muitas vezes ultrapassa o processo de escolarização formal.

Atentamos o estudo para um olhar crítico e emancipatório no sentido de priorizarmos a importância destes espaços como educativos, e estarmos em constante prática e luta para que realmente seja efetivado e reconhecido no âmbito educacional, pois acreditamos a educação não formal e a pedagogia social nos instiga a pensar no respeito às diferenças, no diálogo como instrumento de mediação e na socialização entre o sujeito, a cultura e o mundo social.

\section{REFERÊNCIAS}

ALBA, C. Tecnologias para Transforma a Educação. Porto Alegre: Artmed, 2006.

COLL, C; MAURI, T.; ONRUBIA, J. A incorporação das tecnologias de informação e da comunicação na educação: do projeto técnico-pedagógico às práticas de uso. Porto Alegre: Artmed, 2010.

COUTINHO, A. F. Filantropia em educação no Brasil: a outra face da oferta de educação básica aos pobres ou demissão do Estado? [S.1.: s.n.], 2009.

DEMO, P. Cidadania Tutelada e Cidadania Assistida. Campinas, São Paulo: Autores Associados, 199F

FERNANDES, R. S; GARCIA, V. A. Educação não formal: campo de/em formação. Revista Profissão Docente, v. 6, n. 13, 2006.

FERREIRA, E. C. O uso dos audiovisuais como recurso didático. 2010.

FREIRE, P. O caminho se faz caminhando: conversas sobre educação e mudança social. 4. ed. Petrópolis-RJ: Vozes, 2003.

FREIRE, P. Pedagogia da Autonomia: saberes necessários à prática educativa. 35. ed. São Paulo: Paz e Terra, 2007. (Coleção Leitura) 
LIBÂNEO. Pedagogia e pedagogos, para quê? Cadernos de Pesquisa, v. 37, n. 131, 2007.

SILVA, R. D.; SOUZA NETO, J. C. D.; MOURA, R. A. D. Pedagogia social. São Paulo: Expressão e Arte, 2009.

SIMSON, O. R. M. V.; PARK, M. B.; FERNANDES, R. S. ( et al.). Educação não formal: um conceito em movimento. In: Visões singulares, Conversas plurais. São Paulo, v. 3, p. 13-41, 2007.

\section{Como citar este artigo:}

FERREIRA, Daniella Caroline Rodrigues Ribeiro; SANTOS, Adriana Regina de Jesus. A educação não formal e sua interface com a pedagogia social: conceito, contexto e proposições da formação do sujeito cidadão. Revista Ibero-Americana de Estudos em Educação, Araraquara, v. 14, n. 4, p. 2275-2286, out./dez., 2019. e-ISSN: 1982-5587. DOI: https://doi.org/10.21723/riaee.v14i4.11975

Data de Submissão: 11/12/2018

Revisões requeridas: 22/02/2019

Aceite em: 15/05/2019

Publicado em: 02/09/2019 